\title{
Risk Factors Analysis and Management of Cardiometabolic-Based Chronic Disease in Low- and Middle-Income Countries
}

\author{
Chaitanya Dutt', Joao Eduardo Nunes Salles ${ }^{2}$, Shashank Joshi ${ }^{3}$, Tiny Nair ${ }^{4}$, Subhankar Chowdhury ${ }^{5}$, \\ Ambrish Mithal ${ }^{6}$, Viswanathan Mohan $\mathbb{D}^{7}$, Ravi Kasliwal ${ }^{8}$, Satyawan Sharma ${ }^{9}$, Jan Tijssen ${ }^{10}$, Nikhil Tandon ${ }^{11}$
}

'Research and Development, Torrent Pharmaceuticals Ltd, Ahmedabad, Gujarat, India; ${ }^{2}$ Discipline of Endocrinology, Medical Sciences of Santa Casa de São Paulo, São Paulo, Brazil; ${ }^{3}$ Department of Endocrinology, Lilavati Hospital, Mumbai, Maharashtra, India; ${ }^{4}$ Department of Cardiology, PRS Hospital, Thiruvananthapuram, Kerala, India; ${ }^{5}$ Department of Endocrinology, Institute of Post-Graduate Medical Education and Research and Seth Sukhlal Karnani Memorial Hospital, Kolkata, West Bengal, India; ${ }^{6}$ Department of Endocrinology \& Diabetes, Max Healthcare, New Delhi, India; ${ }^{7}$ Madras Diabetes Research Foundation, Chennai, Tamil Nadu, India; ${ }^{8}$ Medanta- The Medicity, Gurgaon, Haryana, India; ${ }^{9}$ Department of Cardiology, Bombay Hospital and Medical Research Center, Mumbai, Maharashtra, India; ${ }^{10}$ Academic Medical Center - University of Amsterdam, Amsterdam, the Netherlands; "'Department of Endocrinology, All India Institute of Medical Sciences, New Delhi, India

Correspondence: Chaitanya Dutt, Research \& Development, Torrent Pharmaceuticals Ltd., Ahmedabad, Gujarat, India, Tel +9I 982560690I, Email Cdutt@torrentpharma.com

\begin{abstract}
The epidemic of obesity or adiposity-based chronic diseases presents a significant challenge with the rising prevalence of morbidities and mortality due to atherosclerotic cardiovascular diseases (ASCVD), especially in low- and middle-income countries (LMIC). The underlying pathophysiology of metabolic inflexibility is a common thread linking insulin resistance to cardiometabolic-based chronic disease (CMBCD), including dysglycemia, hypertension, and dyslipidemia progressing to downstream ASCVD events. The complex CMBCD paradigm in the LMIC population within the socio-economic and cultural context highlights considerable heterogeneity of disease predisposition, clinical patterns, and socio-medical needs. This review intends to summarize the current knowledge of CMBCD. We describe recently established or emerging trends for managing risk factors, assessment tools for evaluating ASCVD risk, and various pharmacological and nonpharmacological measures particularly relevant for LMICs. A CMBCD model positions insulin resistance and $\beta$-cell dysfunction at the summit of the disease spectrum may improve outcomes at a lower cost in LMICs. Despite identifying multiple pathophysiologic disturbances constituting CMBCD, a large percentage of the patient at risk for ASCVD remains undefined. Targeting dysglycemia, dyslipidemia, and hypertension using antihypertensive, statins, anti-glycemic, and antiplatelet agents has reduced the incidence of ASCVD. Thus, primordial prevention targeting pathophysiological changes that cause abnormalities in adiposity and primary prevention by detecting and managing risk factors remains the foundation for CMBCD management. Therefore, targeting pathways that address mitochondrial dysfunction would exert a beneficial effect on metabolic inflexibility that may potentially correct insulin resistance, $\beta$ cell dysfunction and, consequently, would be therapeutically effective across the entire continuum of CMBCD.
\end{abstract}

Keywords: mitochondrial modulator, insulin resistance, diabetes mellitus, dyslipidemia hypertension, non-high-density lipoproteincholesterol, triglycerides, apolipoprotein B

\section{Introduction}

The Global Burden of Disease reports a dramatic increase in the prevalence of type 2 diabetes mellitus (T2DM) in low- and middle-income countries (LMIC). The prevalence is rapidly increasing due to the ageing of societies and the global obesity epidemic. ${ }^{1}$ Of the estimated 425 million people with diabetes worldwide, three out of four people currently live in LMICs, and increasing numbers of children and young adults have been diagnosed with the disease. ${ }^{2}$ Adiposity-based chronic disease (derangements in adipose tissue function actively contributing to metabolic diseases) has emerged as a health issue of epidemic proportions. It has become the leading cause of morbidity and mortality due to cardiovascular disease (CVD). ${ }^{3}$ The global agestandardized prevalence of diabetes in adults has increased from $4.3 \%$ to $9.0 \%$ in men and $5.0 \%$ to $7.9 \%$ in women since $1990 .{ }^{4}$

Received: 11 August 2021 Accepted: 19 November 2021

Published: 16 February 2022 
Given the growing size of the problem, systematic approaches are urgently needed for detecting individuals early and for treating multiple cardiometabolic risk factors to reduce risk of expensive and difficult to treat complications.

Adopting an integrated approach by targeting multiple risk factors such as weight, glycated hemoglobin (HbA1c), systolic blood pressure (SBP), non-high-density cholesterol (nHDL-C) and low-density lipoprotein cholesterol (LDL-C) allows the detection of a high proportion of the population at risk and helps formulate actionable preventive care plans to improve outcomes at lower costs. Recently, the American Association of Clinical Endocrinologists has developed a new model, "dysglycemia-based chronic disease" (DBCD), which positions insulin resistance, prediabetes, T2DM, and CVD along a continuous spectrum. ${ }^{5}$ Further, the cardiometabolic-based chronic disease (CMBCD) model describes the genetics, environment, and behavior as an upstream event to DBCD that are the early primary drivers of adiposity and dysglycemia leading to cardio-metabolic complications. ${ }^{6}$ There is evidence to suggest that the phenomenon of derangement of metabolic flexibility or metabolic inflexibility is a common thread linking insulin resistance to CMBCD including, dysglycemia, hypertension, and/or dyslipidemia progressing to downstream CVD events. ${ }^{7}$

In the light of this concept, it becomes essential to find practical tools that measure long-term CV risk and effectiveness of interventions considering multiple concurrent risk factors pertinent to the LMIC. Despite identifying numerous pathophysiologic disturbances constituting $\mathrm{CMBCD}$, a large percentage of the individuals at the risk of atherosclerotic cardiovascular disease (ASCVD) remains unidentified. An analysis of six sizeable prospective CV epidemiologic studies assessing the classic risk factors for ASCVD only explained $69 \%$ of observed CV events, leaving 31\% unexplained. ${ }^{8}$ The unaccounted-at risk for CVD could be due to contributions coming from factors not considered in the risk engine, which underscores the importance of measurement tools. The third iteration of the Joint British Society guideline (JBS3), a more recent CV risk prediction model, demonstrated that it was more likely to identify both short- and long-term risks in the large proportion of South Asian patients when compared to other risk assessment tools such as Framingham Risk Scores, ASCVD, and World Health Organization risk prediction charts. ${ }^{9}$

From pragmatic point of view, current medical therapy does not specifically target the underlying pathophysiological defect responsible for the generation of the cardio-metabolic abnormality. The CMBCD concept unifies separate components of an evolving disease pathology into a common thread with multiple targets for simultaneous prevention and treatment to mitigate the rising cardio-metabolic risk. By focusing our efforts on understanding the CMBCD disease spectrum, a comprehensive plan can be strategized for diagnosis, prevention, and treatment in LMICs. This review intends to summarize the current knowledge of the $\mathrm{CMBCD}$ and highlight recently established or emerging risk factors for CVD, especially relevant for LMICs. We will also discuss assessment tools for gauging CVD risk, followed by various pharmacological and non-pharmacological measures and how they relate to the cellular/molecular abnormality responsible for the $\mathrm{CMBCD}$ condition and their effectiveness in reducing the CVD risk.

\section{Cardiometabolic-Based Chronic Disease and Its Pathogenesis}

Insulin and other glucoregulatory hormones provide an integrated set of signals to maintain metabolic flexibility, ie, the capacity of an organism to efficiently switch fuel utilization between fatty acids and glucose based on nutrient availability and requirements. ${ }^{10}$ Metabolic flexibility is maintained by the mitochondria in close coordination with neuroendocrine hormones by metabolizing nutrients and producing energy in the form of adenosine triphosphate, sustaining both energy and metabolic homeostasis. ${ }^{11}$ The equilibrium translates into insulin's metabolic and non-metabolic actions that profoundly influence CV physiology, including glucose uptake in skeletal muscle and adipose tissue, glycogen synthesis in skeletal muscles, suppression of gluconeogenesis, lipolysis inhibition, and modulation of vascular effects. ${ }^{12}$

Insulin resistance, typically characterized by decreased sensitivity and/or blunted insulin response, results from dysregulation of nutrient fluxes. ${ }^{13}$ An erratic selection of fuels in mitochondria interrupts both fatty acid and glucose oxidation, triggering a cascade of events that translates into impaired glucose tolerance/impaired fasting glucose and early T2DM. ${ }^{14}$ Due to impairment in insulin signalling, multiple intracellular steps of glucose metabolism and insulin-stimulated glucose disposal are affected in different organs and tissues, encompassing the liver, skeletal muscle, adipose tissue, pancreas, and the brain. ${ }^{15}$ The pathophysiology is further compounded by impaired $\beta$-cell function, increased oxidative stress and inflammation, endothelial dysfunction, ectopic fat accumulation, and accumulation of advanced glycation end products. ${ }^{7}$ Thus, metabolic inflexibility comprises impaired fat oxidation during fasting with impairment in switching from fat to glucose oxidation after a meal and impairment 


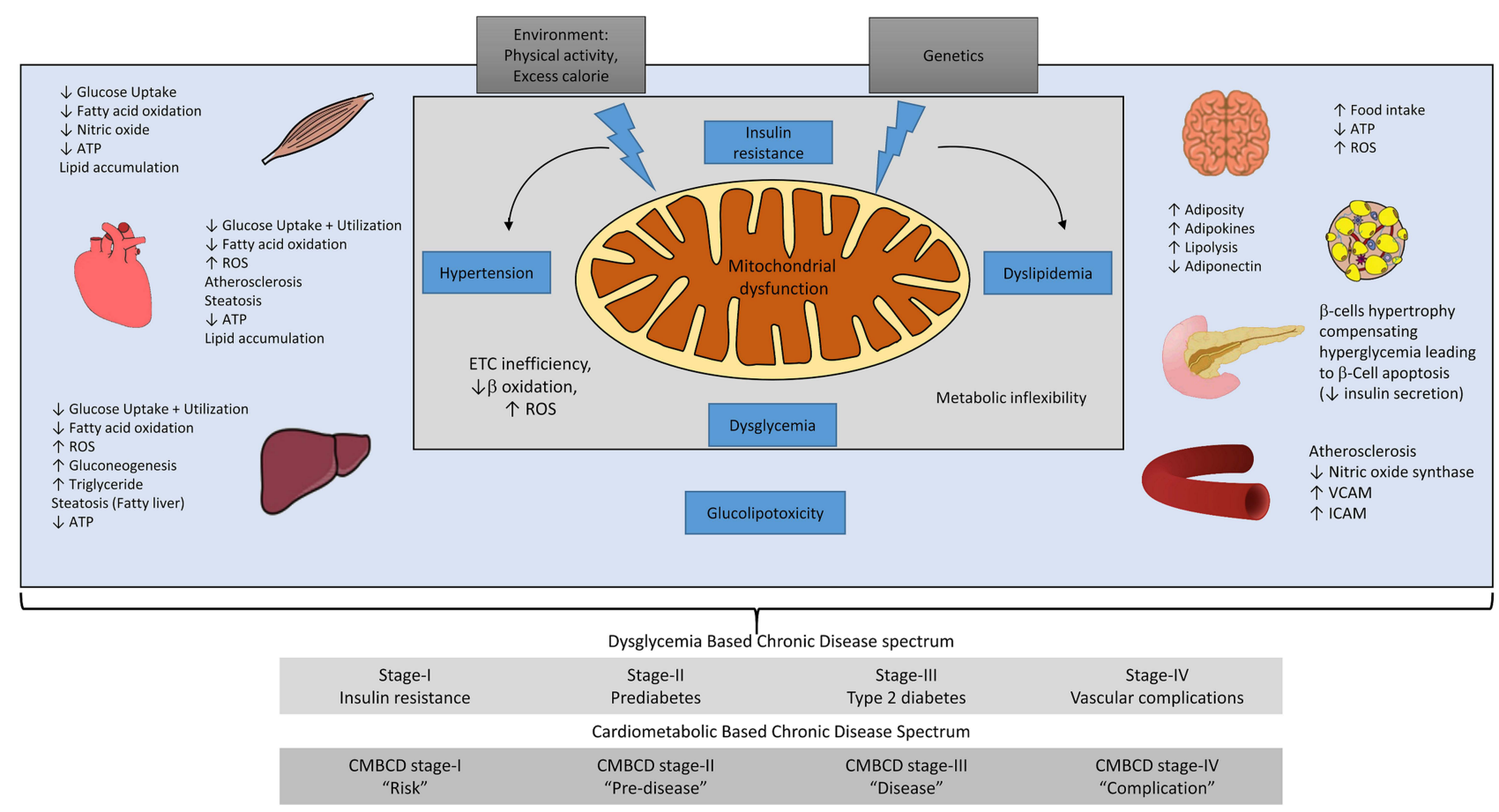

Figure I Mitochondrial dysfunction plays a central role leading to metabolic perturbations in different organ systems, including skeletal muscle, heart, the liver, brain, adipose tissue, pancreas, and blood vessels. Metabolic disturbances, including insulin resistance, dysglycemia, dyslipidemia, and hypertension, act as a metabolic driver concurrently and independently to produce different stages of $D B C D / C M B C D$. The four stages of DBCD and CMBCD are depicted at the bottom.

Notes: Adapted from: Kalra S, Unnikrishnan AG, Baruah MP, Sahay R, Bantwal G. Metabolic and Energy Imbalance in Dysglycemia Based Chronic Disease. Diabetes Metab Syndr Obes. 2021;14:165-184. doi: 10.2I47/DMSO.S286888. (c) 202I Kalra et al. Creative Commons Attribution - Non-Commercial (unported, v3.0) License (http:// creativecommons.org/licenses/by-nc/3.0/). ${ }^{7}$

Abbreviations: ATP, adenosine triphosphate, CMBCD, cardiometabolic-based chronic disease; DBCD, dysglycemia-based chronic disease ROS, reactive oxygen species; ETC, electron transport chain; VCAM, vascular cell adhesion molecule; ICAM, intracellular adhesion molecule.

in $\beta$ oxidation of fatty acids after exercise, which contributes to the development of insulin resistance and eventually sets up the cascade leading up to $\mathrm{CMBCD}$ (Figure 1). ${ }^{7}$

\section{CMBCD Continuum and Challenges in Low- and Middle-Income Countries}

As described earlier, insulin plays a central driving force in glucose and lipid metabolism in multiple organs, including skeletal muscle, adipose tissue, the liver, pancreas, and the heart- these organs and tissue affected by its dysregulation manifesting as a continuum of the disease spectrum of CMBCD. Although the pathophysiology has not been fully elucidated, insulin resistance along with $\beta$-cell dysfunction has been implicated as a primary risk factor for developing a continuum of DBCD and consequently CMBCD. ${ }^{7}$ The $\mathrm{DBCD} / \mathrm{CMBCD}$ care model acknowledges that diabetes is not just a distinct disease characterized by hyperglycemia, but it exists as a continuum. ${ }^{5}$ The model describes four separate stages, stage-I, representing "insulin resistance," stage-II "prediabetes," stage-III "type 2 diabetes," and stage-IV "vascular complications" that includes retinopathy, nephropathy, neuropathy, and related microvascular events. These stages coincide with the CMBCD model, ie, stage-I "risk", stage-II "Pre-disease", stage-III "Disease", stage-IV "complications" (Figure 1). ${ }^{6}$ The complication-centric model emphasizes primary preventive care in the first stage of insulin resistance. Moreover, it possibly improves patients' quality of life, welfare, and overall health at a lower cost. The outcomes are especially important in LMICs, lacking resources and practical solutions to combat the rising burden.

Further, proven therapies and strategies for controlling CMBCD may not be necessarily effective for LMICs. A complex interaction of demographics, socio-economics, and epidemiological factors associated with dietary and physical activity patterns has led to the alarming rise in these countries. ${ }^{16}$ Globalization and acculturation (changes in original cultural pattern assimilating to a different culture) have changed the preference for certain foods and forms of leisure/physical activity. With the ever-increasing migration of population from rural to an urban location, production and distribution of high-fat, energy-dense food, increased processing of food, promotional food marketing has led to 
epidemiology transition in global disease burden. ${ }^{17}$ These evolutions have also encouraged the abandonment of traditional beliefs/behaviors that minimize the risk of overweight and the adoption of beliefs/behaviors that increase the risk of overweight. For example, rural migrants in urban areas tend to abandon traditional diets rich in vegetables and cereal in favor of high caloric food. These migrants have easy access to readily available fast foods, become less reliant on home-cooked food, and have increased snacking between meals. Further, there have also been changes in patterns of physical activity with increased use of motorized transport, increased sedentary recreation, and fewer opportunities for recreational physical activity. These changes have led to a shift in demographic patterns with the rising burden of metabolic disease among the succeeding generations. ${ }^{18,19}$

Furthermore, ever-increasing CVD and deaths in LMICs might also reflect differences in resources, capacity, access, and healthcare systems. In addition, other factors such as poor access to trained healthcare providers, inadequate provision of medications, low health literacy, political instability, limited health budgets, inadequate clinical expertise, environmental pollution, food insecurity, and social disparity may limit the application of standard interventions. ${ }^{20}$ Thus, the consequences are escalating and unsustainable healthcare costs due to $\mathrm{CMBCD}$, which are often preventable.

The complex CMBCD paradigm in the LMIC population within the socio-economic and cultural context highlights considerable heterogeneity of disease predisposition, clinical patterns, and socio-medical needs. As a result, there is an increasing need for more advanced competency and multimodal strategies to control the rising tide of these noncommunicable disease burdens in LMICs. The evidence from randomized controlled trials and pragmatic trials has shown that appropriate preventive care by controlling multiple risk factors and empowering individuals will reduce the socio-economic burden in the long run. ${ }^{21}$ Since secondary and tertiary interventions are costlier, both economically and in terms of disease burden, it becomes logical to intervene and prevent the development of multiple risk factors responsible for $\mathrm{CMBCD}$.

\section{Multi-Factorial Risk Targeting Strategy for Overcoming CMBCD}

Over the last two decades, remarkable progress has been made in some aspects of diabetes care. Advances in preventive care have effectively reduced the burden of hypertension, hyperlipidemia, and hyperglycemia in HICs. However, their incidence in LMIC continues to rise, driving CVD rates. This is especially true in South Asia and Latin America, where barriers at the patient, provider, and system-level result in small proportions of patients achieving treatment goals. In a multicenter survey in South and Central American (SACA) countries, poor glycemic control (fasting blood glucose $\geq 110$ $\mathrm{mg} / \mathrm{dL}$ ) was observed in $78 \%$ of the patients, and the number of patients with $\mathrm{HbAlc}<7.0 \%$ was $43.2 \%{ }^{22}$ In the landmark study, the center for cardiometabolic risk reduction in South Asia (CARRS) surveillance study, $\sim 30 \%$ of known individuals achieved target glycemic control of $<7 \%$ but no improvements in BP control or reductions in smoking. ${ }^{23}$ In the CARRS trial, $70.9 \%$ of the participants predominantly had $\mathrm{HbAlc}$ level $\geq 8 \%$ and systolic blood pressure (SBP) $\geq 140 \mathrm{~mm} \mathrm{Hg}$, $47.1 \%$ had $\mathrm{HbA} 1 \mathrm{c} \geq 8 \%$ and LDL-C $\geq 130 \mathrm{mg} / \mathrm{dL}$, and $18.1 \%$ had all three abnormalities. Additionally, $6.8 \%$ of the participants had pre-existing CVD, and most importantly, $39.4 \%$ had previous microvascular complications. ${ }^{24}$ The multicomponent strategy was associated with the achievement of combined diabetes care goals and larger reductions for each risk factor compared with usual care suggesting that such strategy can be replicable in LMIC.

Several practice guidelines recommend blood pressure targets $<130 / 80 \mathrm{~mm} \mathrm{Hg}$ along with tight glycemic control. The glycemic legacy effect of early intervention in newly diagnosed patients in the UKPDS and individuals with impaired glucose tolerance in a diabetes prevention program has led to long-term reduction of cardiovascular-renal events and all-cause death. ${ }^{25}$ The use of a system-wide strategy to diagnose and treat patients with T2DM early and intensively, along with the use of other medications for organ protection, might induce remission or maintain glycaemic durability with long-term benefits. Steno-2 (Denmark), J.DOIT3 (Japan) studies have demonstrated that multiple interventions, including lifestyle modification (LSM) and pharmacological management for dysglycemia, dyslipidemia, and hypertension using renin-angiotensin system inhibitors, anti-lipids (statins), antihypertensive, reduces micro-and macro-vascular complications. ${ }^{26,27}$ These further translated into a long-term reduction in end-organ damage and supported the cost-effectiveness of the multifactorial treatment in primary healthcare settings. These observations have also led to changes in practice guidelines, which recommend regular assessment of risk factors and complications after accounting for demographic, biomedical, cognitive, psychosocial, and behavioral profiles for individualizing treatment targets and strategies. 
When considering a multifactorial approach, it is important to recognize that diabetic dyslipidemia (a cluster of plasma lipid and lipoprotein abnormalities), is metabolically closely linked to insulin resistance. ${ }^{28}$ Together, triglyceriderich lipoprotein cholesterol (TRL-C) \{chylomicron, very-low-density lipoprotein (VLDL), intermediate-density lipoprotein (IDL-C) $\}$ and small dense LDL, principally all containing apolipoprotein B (apoB) comprise the atherogenic lipid profile or nHDL-C (Figure 2). Thus, the malignant nature of diabetic dyslipidemia is not always revealed by the lipid measures used in clinical practice, as LDL-C levels may remain within the normal range. Large-scale statin trials have shown that despite marked ASCVD risk reduction, the residual risk of ASCVD in statin-treated patients remains as high as $55-70 \% .{ }^{29}$ Similarly, a meta-analysis of 62,154 statin-treated patients in 8 trials (4S, AFCAPS, LIPID, CARDS, TNT, IDEAL, SPARCL, JUPITER) revealed that an increase in one standard deviation resulted in an increase in LDL-C, apoB, and nHDL-C, which further increased the risk of CV events by $13 \%, 14 \%$, and $16 \%$, respectively. ${ }^{30}$ These findings suggest an increased nHDL-C is associated with an increased risk of future CV events, even after controlling LDL-C levels in the normal range with statins. There is ample evidence supporting nHDL-C in predicting residual and long-term ASCVD risk in patients, especially those with diabetes. Subsequently, nHDL-C has already been included as a coprimary target in the previous Expert Consensus of the Lipid Association of India. ${ }^{31}$ The European Society of Cardiology also defines the targets for those at the high-risk and very high risk (Figure 3 ). ${ }^{32}$

Furthermore, evidence from studies evaluating risk factors demonstrated variation in disease pattern/phenotypic differences from socio-cultural differences in diet and/or lifestyle. Four distinct clusters of T2DM were identified in the Indian and Chinese population based on clinical presentation, presence/absence of insulin resistance, and $\beta$ cell dysfunction. ${ }^{33}$ In the Indian population, clusters were termed as severe insulin-deficient diabetes (SIDD), insulin-resistant obese diabetes (IROD), combined insulin-resistant, and deficient diabetes (CIRDD) and mild age-related diabetes (MARD). ${ }^{33}$ On the other hand, the Chinese population had SIDD, severe insulin-resistant diabetes (SIRD), mildobesity-related diabetes (MOD), and MARD. ${ }^{34}$ China National Diabetes and Metabolic Disorders survey could identify clusters similar to the European study with MARD comprised nearly half the participants of the total population studied.

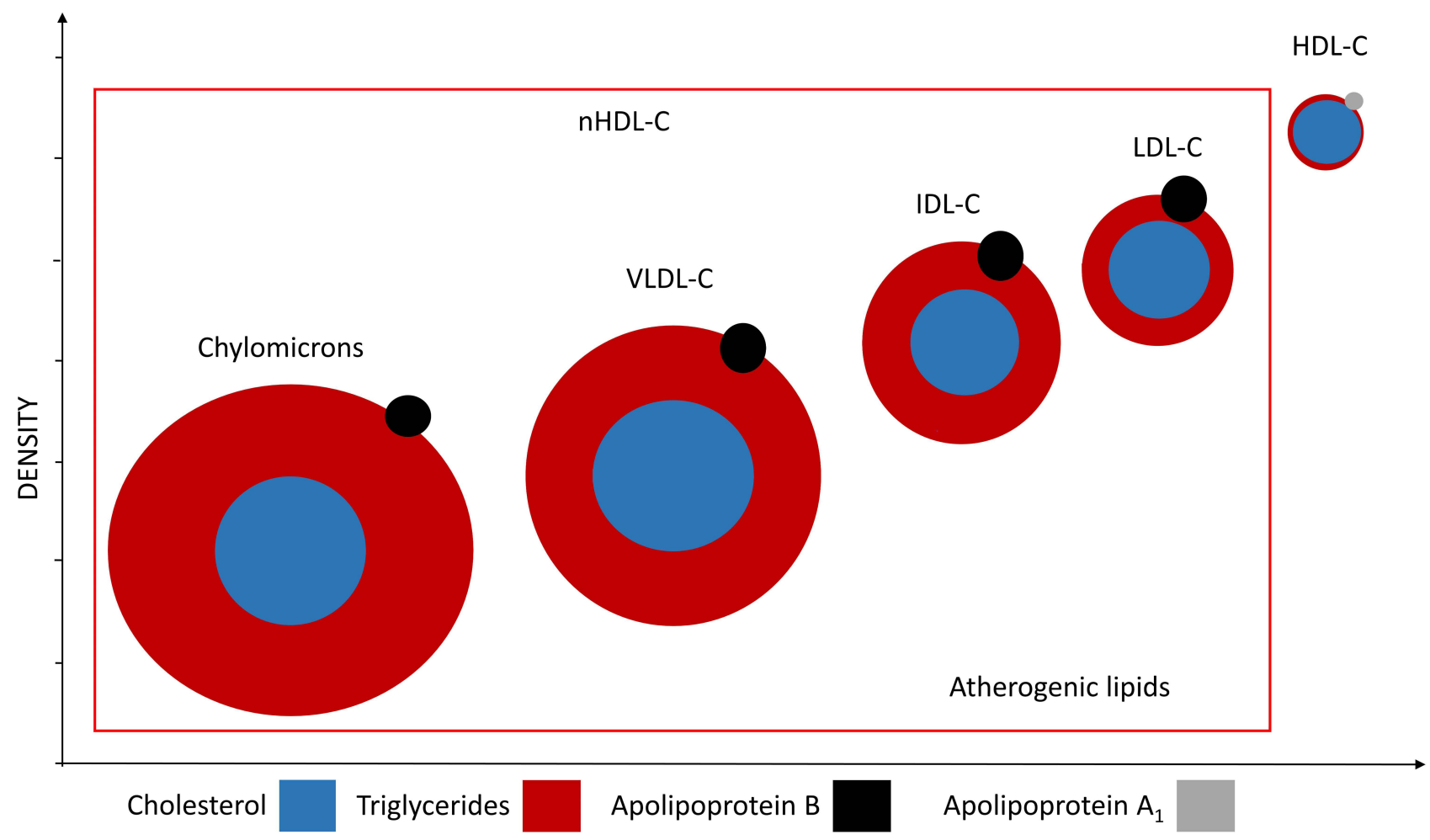

Figure 2 The atherogenic lipoprotein consists of chylomicrons, VLDL-C, IDL-C, and LDL-C.

Abbreviations: HDL-C, high-density lipoprotein cholesterol; IDL-C, intermediate-density lipoprotein-cholesterol; LDL-C, low-density lipoprotein-cholesterol; VLDL-C, very low-density lipoprotein-cholesterol; nHDL-C, non-high-density lipoprotein-cholesterol. 


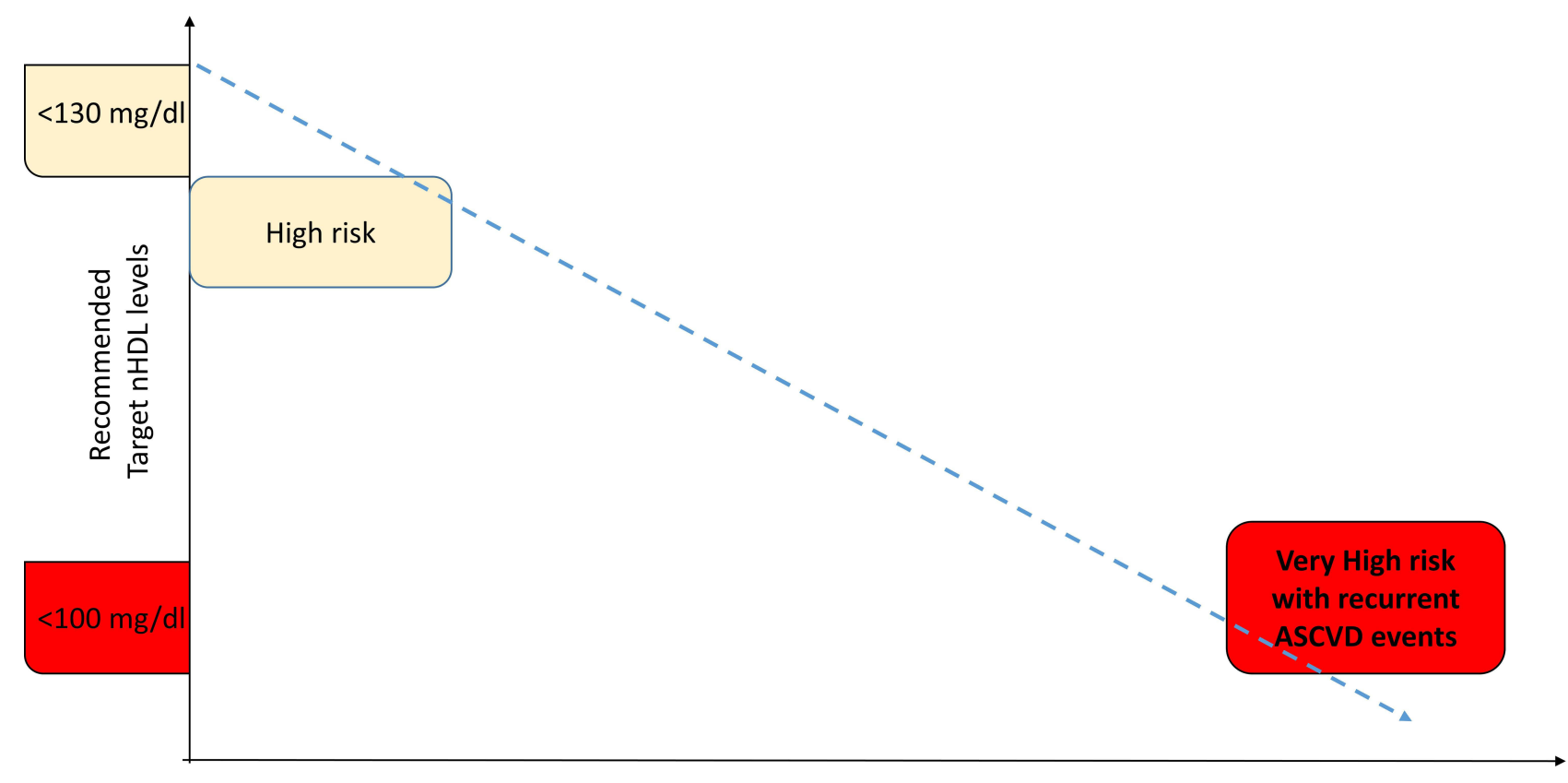

Risk levels

Figure 3 Targets for $\mathrm{nHDL}$ modification to reduce cardiovascular risk. The $\mathrm{nHDL}$ targets should be $2.6 \mathrm{mmol} / \mathrm{L}$ (less than I00 mg/dL) and $3.3 \mathrm{mmol} / \mathrm{L}$ (less than $130 \mathrm{mg} / \mathrm{dL}$ ) in those at very high and high total CV risk, respectively, as per the $2019 \mathrm{ESC} / \mathrm{EAS}$ Guidelines for the management of dyslipidemia.

In contrast to the European studies, the INSPIRED study could identify two distinct phenotypes, CIRDD (7.6\%) and IROD (30.3\%), with a higher risk for nephropathy. These clusters were associated with higher adiposity (increased waist circumference) and insulin resistance that is difficult to control with conventional oral anti-diabetics. ${ }^{33}$

Recognizing the growing burden of hypertension and diabetes and their co-existence as a continuum leading up to CV complications across all segments of the population, as seen in the Indian Council of Medical Research-India Diabetes (ICMR-INDIAB) study, ${ }^{35}$ the Ministry of Health \& Family Welfare, Government of India has initiated an integrated program for screening and managing these conditions under its umbrella scheme National Health Mission and the National Programme for Prevention and Control of Cancer, Diabetes, Cardiovascular Disease, and Stroke. ${ }^{36}$ The adults aged $\geq 30$ years in the community will be encouraged to undergo universal screening for hypertension and diabetes, and subsequently, potential cases will be referred to the higher-level facilities. Under the Integrated Tracking, Referral, Electronic decision support and Care coordination (I-TREC) program, an effort will be made to systematically integrate the management of hypertension and diabetes at all levels of the public healthcare system. ${ }^{37}$

\section{Risk Assessment Strategies and Tools}

The multifactorial nature of ASCVD has led to the development of several multivariable risk assessment tools to evaluate CVD risk, including Framingham risk score, SCORE algorithm, the German PROCAM model, the UK QRISK and QRISK2 equations, World Health Organization risk chart, the 2013 Pooled Cohort risk equations, the Globorisk cardiovascular risk equation, and the JBS3 risk score. However, due to lack of systemic validation in prospective studies and generalizability of results in a specific ethnicity, including LMICs have limited its use in certain populations. The South Asian population (India, Pakistan, Bangladesh, Nepal, Sri Lanka) representing approximately one-quarter of the world's population are particularly at an increased risk of premature CVD due to a combination of environmental and genetic factors; their enhanced susceptibility to CVD is associated with developing CV risk factors at an earlier age. ${ }^{38}$ While the data from North American and European observational studies have informed these cardiovascular risk scores, there is a paucity of data in South Asian populations. Also, earlier comparative studies evaluating some cardiovascular risk calculators have highlighted their poor performance when analyzing ethnic groups. ${ }^{39}$ 
Most recently, the JBS3 risk score was developed using data from the QRISK2 cohort of United Kingdom-based patients, including 320,018 in the derivation and 95,983 South Asian patients in the validation cohorts. The JBS3 risk score predicts both a short-term risk (10-year) and the lifetime risk of CVD using conventional and non-conventional risk factors. It recognizes and encompasses a large patient population at a lower or intermediate 10-year risk but has a high lifetime risk, and in whom long-term exposure to CVD risk drives atherogenesis. These individuals would not likely receive pharmacological therapy but are more likely to adopt risk-preventing strategies such as lifestyle changes, diet, and behavioral therapy.

JBS risk score has been able to identify $65 \%$, the highest proportion of patients with high cardiovascular risk, while ACC/AHA and WHO risk scores using the same patient population identified only $28.7 \%$ and $21.3 \%$, respectively, as the high risk among migrant South Asian population ${ }^{40}$ (Figure 4). Importantly, this large variability between risk prediction models is supported by Bansal and co-workers who reported similar findings through their analysis of a native South Asian population. ${ }^{41}$ Therefore, the JBS3 risk score can help identify and consequentially manage the sizable number of individuals at lower short-term risk through early LSM and by use of approved pharmacotherapy in the high-risk populations.

\section{CMBCD Management}

Extensive research has shown that individuals with a lower risk profile in the middle age have substantially lowered the $\mathrm{CV}$ and non-CV mortality, improved survival, and also lowered lifetime risk of CVD events compared to those without

\section{Year Cardiovascular Risk for the Four Risk Assessment Models}

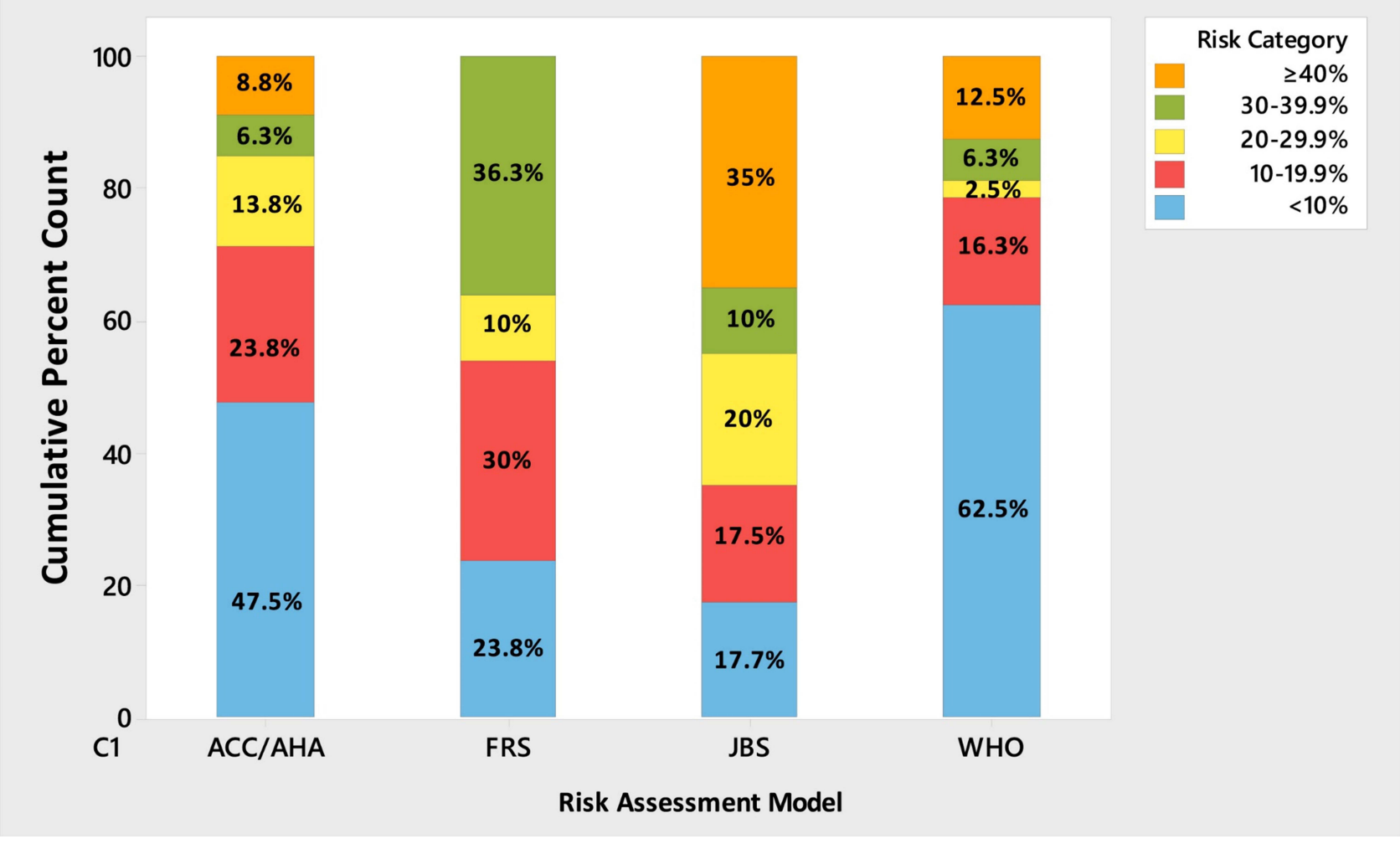

Figure 4 JBS3 risk score (65\%) identified the highest proportion of patients as "high risk," ie, >20\% I0-year cardiovascular risk vs ACC/AHA risk score (28.9\%), FRS (46.3\%), WHO risk score (21.3\%).

Notes: Reprinted with permission from: Findlay SG, Kasliwal RR, Bansal M, Tarique A, Zaman A. A comparison of cardiovascular risk scores in native and migrant South Asian populations. SSM Popul Health. 2020;1 I:100594. doi:10.1016/j.ssmph.2020.100594. (C 2020 The Author(s). Published by Elsevier Ltd. CC BY-NC-ND license (http:// creativecommons.org/licenses/by-nc-nd/4.0/). ${ }^{40}$

Abbreviations: FRS, Framingham Risk Score; JBS, Joint British Society; ACC/AHA, American College of Cardiology/American Heart Association; WHO, World Health Organisation. 
the risk profile. ${ }^{42}$ Moreover, those with a low CVD risk profile are also associated with a higher quality of life and lower medical expenses, which is crucial in LMICs. ${ }^{43}$ The clinical trial experiences, observational studies, and real-world programs in HICs have provided evidence that multiple lifestyle-related factors need to be targeted simultaneously to achieve a low CVD risk profile. ${ }^{44}$ However, socio-cultural and healthcare systems in the LMICs may play differential effects for pharmacological therapies on CVD. For instance, in the Anti-hypertensive and Lipid-Lowering Treatment to Prevent Heart Attack Trial (ALLHAT), the African Americans in the renin-angiotensin blocker's arm experienced a higher risk for strokes and other CVD events. ${ }^{45}$ Among LMICs, particularly in rural regions in a country like India, where $70 \%$ of the population resides, poor infrastructure in low resource settings continues to be a challenge. Besides, there is minimal interaction with the primary care physician who could screen and deliver preventive care. Therefore, there is necessity for improving cultural sensitivity among the healthcare provider for delivery of comprehensive care.

Furthermore, the guidelines in LMICs are inadequate in terms of applicability, clarity, and dissemination plan. ${ }^{46}$ The reduction in CVD seen in HICs has been primarily attributed to the healthcare policies introduced to reduce risk factors and strengthen the primary healthcare system. In contrast, LMICs with steadily rising CVD have not benefitted because the policies for reducing risk factors have not been widely adopted. Also, the therapies are not affordable for most people, and there is a lack of social protection such as insurance for a large fraction of the population. Therefore, concerted efforts are needed in LMICs for ensuring reliable access to healthcare, delivery of localized guidelines, and strengthen the primary preventive strategies.

Nonetheless, metabolic drivers, underlying $\mathrm{CMBCD}$ are influenced by modifiable risk factors that serve as interventional targets to prevent downstream cardiovascular disease (CVD). Thus, targeting the upstream drivers, namely, dysglycemia, dyslipidemia, and hypertension that interact at the level of insulin resistance, could potentially prevent micro- as well as macro-vascular complications. Interventions can be applied at each CMBCD stage, depending on pathophysiological targets and clinical goals. If implemented successfully, this approach would facilitate earlier and more effective intervention, in contrast with practice standards that focus on downstream CVD presentations and complications.

\section{Non-Pharmacological Intervention Overcoming Cultural Barriers}

Primary care physician often overlooks the crucial sociocultural factors that represent significant barriers that can challenge attainment of target goals of treatment. ${ }^{47} \mathrm{~A}$ key element to overcome these barriers is to communicate during clinician-patient interaction effectively. The treating physician should rapidly assess social and cultural factors that might influence comprehensive care including, the patient's educational status, health literacy, family support, employment status, availability of health insurance, financial health, dietary patterns, and access to medication. By acknowledging the cultural perceptions of health unique to each individual, the physician should further specifically tailor effective programs and treating strategies using information and support in suitable language and culturally appropriate settings. Therefore, documentation of key insights and risk factors from these initial evaluations will help maintain continuity of care and may prevent adverse health outcomes arising due to sociocultural barriers.

\section{Lifestyle Management (Caloric Restriction and Exercise)}

Primordial prevention targeting pathophysiological changes that cause abnormalities in adiposity and primary prevention by detecting risk factors is the foundation for building the measures to prevent or delay the development of the underlying defect of insulin resistance. LSM has been the cornerstone for managing chronic debilitating diseases associated with insulin resistance. ${ }^{48}$ Elimination of modifiable risk factors, including an unhealthy lifestyle, allows for the prevention of $80 \%$ of CVD. ${ }^{49}$ The data on prevention trials in high-risk populations for T2DM in LMICs are limited. In China, 30-year follow-up data from the Da Qing Diabetes Prevention Outcome Study showed that LSM in individuals with prediabetes reduces long-term risks of T2DM, microvascular complications, CVD, CV mortality, and all-cause mortality. ${ }^{50}$ Similarly, in the Indian Diabetes Prevention Programme, lifestyle intervention among participants with impaired glucose tolerance resulted in substantial reductions in T2DM incidence among participants. ${ }^{51}$ 
Research evidence show that a diet containing an abundance of fruits and vegetables, fish, whole grains offers significant protection and lowers CVD risk. ${ }^{52}$ The National Dietary Guidelines Consensus Group recommends reducing carbohydrates and high glycemic foods, preferential intake of complex carbohydrates, higher intake of fiber and unsaturated fats, reduction in transfatty acids, and salt intake, etc. ${ }^{53}$ Traditional diets in LMIC, once rich in whole grains and dietary fibers, now include highly refined carbohydrates, such as polished white rice and refined flours. Global Nutrition and Epidemiologic Transition Initiative recommended increasing whole grain and cereal fiber consumption and reducing total and high-glycemic index carbohydrate strategies to prevent T2DM and CVD in the general population. ${ }^{54}$ Moreover, the WHO recommended taxation of sugar-sweetened beverages based on the association between consumption of them and increased rates of overweight and obese people. ${ }^{55}$ Thus, effective policy implementation strategies for improving healthy consumption of food may mitigate the rise of the epidemic of CMBCD in LMICs.

Further, physical activity and exercise have also been extensively studied for their effect on metabolic flexibility. ${ }^{11}$ Evidence shows that exercise reduces glucose intolerance and cardiometabolic risk factors by increasing insulin sensitivity. For example, a daily threshold for a relatively small volume of physical activity is protective in reducing the transition of those with impaired glucose tolerance to frank T2DM. ${ }^{56}$ The AHA/ACC recommends $150 \mathrm{~min} /$ week of moderate to vigorous physical activity or 75 minutes per week of vigorous-intensity physical activity. ${ }^{57}$ Likewise, the World Health Organization launched the process to develop a new Global Action Plan to promote physical activity and requested to develop global monitoring and reporting systems to reduce the NCD burden. ${ }^{58}$

Lifestyle interventions also reduce hypertension in the individual without impaired glucose tolerance, which has led to establishing a systematic, individual-level prevention program for patients with T2DM in HICs. ${ }^{59} \mathrm{~A}$ comprehensive LSM, including group therapy, behavioral strategies, frequent monitoring of food intake, and high regular physical activity levels, is recommended to reduce the morbidity and mortality related to the CMBCD disease spectrum, especially in LMIC. $^{60}$ In the resource constraint setting, a team-based care approach is an effective strategy for preventing CVD, and where appropriate, the use of an approved pharmacotherapy is recommended.

\section{Pharmacological Interventions}

Most LSM interventions have been shown to induce only modest changes in targeted behaviors but have been proven difficult to achieve in the real world. Approximately $25 \%$ of LSM programs reduce treatment success due to noncompliance leading to a general perception that almost no one succeeds in the long-term maintenance. ${ }^{61}$ Therefore, secondary prevention patient-strategies come into play at this stage to prevent disease progression or a secondary complication by addressing underlying pathophysiology. These are targeted at the fundamental metabolic drivers that are deranged, ie, dysglycemia, dyslipidemia, and the secondary pro-inflammatory, pro-thrombotic vascular changes leading to hypertension, secondary to persistent insulin resistance.

In the last decade, the availability of multiple treatment choices for managing T2DM and complications has made the therapeutic decision more complicated. As supported by multiple RCTs, blood glucose reduction, blood pressure, and lipid levels using a polypill approach have improved multiple risk factors in both LMICs and HICs. ${ }^{24,26,27,62}$ A subsequent meta-analysis of these randomized controlled trials substantiated that reduction of $\mathrm{HbA1c}$ by $0.9 \%$, SBP by $10 \mathrm{mmHg}$, and LDL-C concentration by $39 \mathrm{mg} / \mathrm{dl}$ individually reduced the risk of CVD, all-cause of death, or both by 10-20\%, independent of other risk factors. ${ }^{63}$ Although the population values of HbA1c, blood pressure, and LDL cholesterol concentration are not known in many cases, we assume that most diagnosed individuals can benefit from a further reduction in risk factors.

An increasing body of evidence has accumulated, indicating a link between mitochondrial dysfunction and insulin resistance. ${ }^{14}$ This has opened a window for new therapeutic strategies aimed to preserve/ameliorate mitochondrial function. Insulin-sensitizing agent thiazolidinediones (TZD), a peroxisome proliferator-activated receptor-gamma (PPAR- $\gamma$ ), exerts an anti-diabetic effect by altering transcription of several genes involved in glucose and lipid metabolism and energy balance. ${ }^{64}$ However, TZDs are commonly associated with weight gain features and a possible risk of bladder cancer. Studies have attempted to elucidate the mechanisms behind the apparent paradox found a favorable shift in fat distribution from visceral to subcutaneous adipose depots that are associated with improvements 
in hepatic and peripheral tissue insulin sensitivity. ${ }^{65}$ These observations may have clinical relevance to TZDs' mechanism of action, as in humans, visceral adiposity is associated with insulin resistance.

Newer agents, such as sodium-glucose cotransporter 2 inhibitors (SGLT2i) and glucagon-like peptide 1 receptor agonists (GLP-1RA), in particular, have gained traction in the last few years; however, they are relatively expensive and have limited availability. These drugs are indicated for patients deemed as "very high risk" or "high risk," including those with T2DM and CVD, diabetes without ASCVD but with other target organ damage (proteinuria, renal impairment defined as eGFR $<30 \mathrm{~mL} / \mathrm{min} / 1.73 \mathrm{~m}^{2}$, left ventricular hypertrophy, or retinopathy), or those with diabetes with three or more major risk factors (aged 50 years or older, hypertension, dyslipidemia, smoking, and obesity), T1DM duration of $>20$ years, or diabetes duration $\geq 10$ years without target organ damage, plus any other additional risk factor as per the ESC guideline. ${ }^{63}$ Table 1 summarizes medication used for the treatment of T2DM.

Unfortunately, the benefits of SGLT2i are not without risk. These are prescribed with caution in those with T2DM and are also not approved for T1DM, mainly due to the risk of ketoacidosis. ${ }^{66}$ Besides, they have been shown to induce hyperglucagonemia and stimulate hepatic gluconeogenesis. The glucosuria produced by SGLT2i stimulates endogenous glucose production (EGP), and that the increase in EGP offsets by $50 \%$ the amount of glucose lost in the urine ${ }^{67}$ The increase in EGP in individuals with T2DM is paradoxical in that it occurs while the plasma glucose concentration is within the hyperglycemic range. Finally, there is an increased susceptibility to genital and urinary tract infections.

Table I Summary of Medication Used for Treatment of Type 2 Diabetes Mellitus

\begin{tabular}{|c|c|c|c|}
\hline Drug & Mechanism of Action & Clinical Effects & Side Effects \\
\hline Metformin ${ }^{70}$ & $\begin{array}{l}\text { i. Exerts a weak and reversible selective } \\
\text { inhibition of Complex-I of mitochondrial } \\
\text { respiratory chain leading to secondary } \\
\text { activation of AMPK, regulating glucose and } \\
\text { lipid metabolism. }{ }^{71} \\
\text { ii. Enhances peripheral muscle glucose } \\
\text { uptake and utilization by increasing insulin } \\
\text { sensitivity } \\
\text { iii. Reduces hepatic gluconeogenesis and } \\
\text { intestinal glucose absorption } \\
\text { iv. Alters endocrine function in the } \\
\text { pancreas }\end{array}$ & $\begin{array}{l}\text { i. Reduces blood glucose }(\mathrm{HbAlc}) \text { without } \\
\text { causing hypoglycemia and weight gain. } \\
\text { ii. Reduces CVD risk } \\
\text { iii. Reduces LDL and increases HDL } \\
\text { iv. Decreases food intake and body weight } \\
\text { v. Modulates inflammatory markers }\end{array}$ & $\begin{array}{l}\text { Lactic acidosis (rare), abdomina } \\
\text { distention, diarrhea, nausea, } \\
\text { vitamin BI2 deficiency }\end{array}$ \\
\hline $\begin{array}{l}\text { SGLT-2 } \\
\text { inhibitors }^{72,73}\end{array}$ & $\begin{array}{l}\text { i. Inhibit glucose reabsorption in the } \\
\text { proximal tubule of the kidney leading to } \\
\text { diuresis and natriuresis } \\
\text { Other potential mechanisms } \\
\text { ii. Improve cardiac mitochondrial } \\
\text { bioenergetics } \\
\text { iii. Reduce inflammation }\end{array}$ & $\begin{array}{l}\text { i.Reduce incidence of CV deaths and heart } \\
\text { failure hospitalization in people with and } \\
\text { without T2DM and those with and } \\
\text { without prevalent heart failure. } \\
\text { ii. Reduce blood glucose/HbAlc } \\
\text { ii. Reduce in blood pressure } \\
\text { iv. Increase HDL-C and TGs } \\
\text { v. Reduce weight }\end{array}$ & $\begin{array}{l}\text { Urinary tract infection, genital } \\
\text { mycotic infection, Increased } \\
\text { urination } \\
\text { Dyslipidemia (increase in LDL-C) }\end{array}$ \\
\hline Sulfonylureas ${ }^{74}$ & $\begin{array}{l}\text { i. Increase release of insulin through the } \\
\text { stimulation of pancreatic beta cells by } \\
\text { binding to a subunit of potassium ATP- } \\
\text { dependent channels (sulphonylurea } \\
\text { receptor). } \\
\text { ii. Increase growth and sensitivity of insulin } \\
\text { receptors on other tissues like adipocytes } \\
\text { and triggering hepatic gluconeogenesis }\end{array}$ & i. Reduce blood glucose (HbAlc) & $\begin{array}{l}\text { Hypoglycemia, } \\
\text { weight gain }\end{array}$ \\
\hline
\end{tabular}

(Continued) 
Table I (Continued).

\begin{tabular}{|c|c|c|c|}
\hline Drug & Mechanism of Action & Clinical Effects & Side Effects \\
\hline Thiazolidinediones $^{75}$ & $\begin{array}{l}\text { Regulate gene expression through binding } \\
\text { to peroxisome proliferator-activated } \\
\text { receptor-gamma (PPAR-gamma) in skeletal } \\
\text { muscle, adipose tissue, and hepatocytes, } \\
\text { causing } \\
\text { i. Decrease hepatic gluconeogenesis, } \\
\text { ii. Increase insulin-dependent glucose } \\
\text { uptake in skeletal muscle and adipose } \\
\text { tissue. } \\
\text { iii. Increase adiponectin levels }\end{array}$ & $\begin{array}{l}\text { i. Reduce blood glucose (HbAlc) without } \\
\text { causing hypoglycemia. } \\
\text { ii. Improve insulin sensitivity in insulin- } \\
\text { resistant individuals } \\
\text { iii. Increase HDL-C } \\
\text { iv. Reduce sdLDL and TGs } \\
\text { v. Increases adiponectin } \\
\text { vi. Reduces blood pressure } \\
\text { vii. Reduces inflammation } \\
\text { viii. Reduces procoagulant state } \\
\text { ix. Preserves } \beta \text {-cell function }\end{array}$ & $\begin{array}{l}\text { Edema, congestive heart failure } \\
\text { (rosiglitazone), weight gain, } \\
\text { fractures, risk of bladder cancer } \\
\text { (pioglitazone, rare) }\end{array}$ \\
\hline DPP-4 inhibitor ${ }^{76}$ & $\begin{array}{l}\text { i. Prevents the degradation of glucagon-like } \\
\text { peptide-I and enhances its insulinotropic } \\
\text { effects }\end{array}$ & $\begin{array}{l}\text { i. Reduces fasting and postprandial blood } \\
\text { glucose (HbAlc) without causing } \\
\text { hypoglycemia } \\
\text { ii. Weight neutral }\end{array}$ & $\begin{array}{l}\text { Increase the risk of acute } \\
\text { pancreatitis (rare). } \\
\text { Isolated cases of arthralgia and } \\
\text { bullous pemphigoid }\end{array}$ \\
\hline $\begin{array}{l}\text { GLP-I receptor } \\
\text { agonist }^{77,78}\end{array}$ & $\begin{array}{l}\text { i. Regulates the expression of beta-cell } \\
\text { genes by inhibiting beta-cell apoptosis, } \\
\text { preventing beta-cell glucolipotoxicity, and } \\
\text { improving beta-cell function, causing } \\
\text { ii. Improves insulin sensitivity } \\
\text { iii. Decreases glucagon } \\
\text { iv. Slows gastric emptying } \\
\text { v. Increases satiety } \\
\text { vi. Reduces free fatty acid }\end{array}$ & $\begin{array}{l}\text { i. Reduces fasting and postprandial blood } \\
\text { glucose (HbAlc) without causing } \\
\text { hypoglycemia } \\
\text { ii. Reduces bodyweight } \\
\text { iii. Reduces systolic blood pressure } \\
\text { iv. Reduction in LDL-C and total } \\
\text { cholesterol. } \\
\text { v. Reduces cardiovascular and } \\
\text { microvascular complications }\end{array}$ & $\begin{array}{l}\text { Common: Gastrointestinal } \\
\text { symptoms, including nausea, } \\
\text { vomiting, diarrhea. } \\
\text { Others: Headache and } \\
\text { nasopharyngitis }\end{array}$ \\
\hline $\begin{array}{l}\text { Alpha glycosidase } \\
\text { inhibitor }^{79}\end{array}$ & $\begin{array}{l}\text { i. Inhibits the absorption of carbohydrates } \\
\text { from the small intestine, competitively } \\
\text { inhibit an enzyme that converts complex } \\
\text { carbohydrates to simple }\end{array}$ & $\begin{array}{l}\text { i. Reduces postprandial blood glucose } \\
\text { (HbAlc) }\end{array}$ & $\begin{array}{l}\text { Gastrointestinal: Flatulence, } \\
\text { diarrhea, abdominal pain }\end{array}$ \\
\hline
\end{tabular}

Abbreviations: ATP, adenosine triphosphate; CVD, cardiovascular disease; DPP-4, dipeptidyl peptidase-4; GLP-I, glucagon-like peptide-I; HbAIc, glycated hemoglobin; HDL-C, high-density lipoprotein-cholesterol; LDL-C, low-density lipoprotein-cholesterol; sdLDL-C, small density low-density lipoprotein-cholesterol; SGLT-2, sodiumglucose cotransporter 2 inhibitor; TG, triglyceride.

Likewise, semaglutide once-weekly SC and oral once-daily have been extensively studied in the SUSTAIN and PIONEER trials, respectively, for CVD risk reduction. There was a reduced relative and absolute risk of MACE with semaglutide vs comparators across the spectrum of baseline CV risk scores; however, the risk reduction was small, and there was a trend $(\mathrm{p}=0.06)$ towards the largest relative risk reduction occurring in those with lowest $\mathrm{CV}$ risk. ${ }^{68}$ Besides inconvenience in SC dosing, patients and the treating physicians have reported non-adherence to the treatment with GLP1RA in large part due to gastrointestinal side effects. Also, most of these trials on SGLT2i and GLP-1RA have reported unprecedented CV benefits in secondary prevention of CVD and outcomes. ${ }^{69}$

The early onset of metabolic derangement with a high lifetime risk of developing complications in the young population might benefit most from drugs with a low risk of hypoglycemia and weight gain. These elements provide a strong business case for investing in intervention controlling multiple risk factors. Newer agents certainly have a role to play in managing risk factors for CVD while balancing side-effects and affordability issues. Due to the critical standpoint of mitochondria upstream of CMBCD in the multiple target organs, it seems to be an attractive strategy to prevent insulin resistance. ${ }^{7}$ Targeting the metabolic inflexibility and correcting the mitochondrial defect could offer ways of correcting the fundamental underlying defect and improve the entire spectrum of CMBCD. 


\section{Conclusion}

Clinicians need to recognize cardiometabolic-based chronic disease that encompasses insulin resistance, dysglycemia, dyslipidemia, hypertension, and associated micro- and macro-vascular complications. A comprehensive improvised assessment of risk is necessary for low- and middle-income countries with high young-onset diabetes rates with multiple phenotypes. In the diverse population, intensive focus is needed for educating patients to overcome sociocultural barriers, ensure reliable access to healthcare, develop and deliver guidelines that can be applied locally, and strengthen the primary preventive strategies to mitigate the increasing burden of CMBCD.

Structured lifestyle change involving healthy eating patterns and physical activity, judicious use of cardioprotective pharmacotherapy based on data points for patients with established ASCVD or risk factors is warranted in resource constraint settings. Sustained reduction of common cardiometabolic risk factors using drugs that reduce lipids, blood glucose, and systolic blood pressure is currently recommended. Future research should focus on pharmacological therapy targeting mitochondrial dysfunction upstream of $\mathrm{CMBCD}$, which can restore metabolic flexibility and manage multiple interlinked conditions associated with insulin resistance, including dysglycemia, hypertension, and dyslipidemia.

\section{Acknowledgments}

The authors received no direct compensation related to the development of the manuscript. Writing and editorial support was provided by Dr Suchit Kumbhare and Dr Deepa Joshi.

\section{Disclosure}

Dr Chaitanya Dutt is an employee of Torrent Pharmaceuticals Ltd. Prof. Dr Joao Eduardo Nunes Salles reports personal fees from AstraZeneca, Novo Nordisk, Eli Lilly, MSD, Boehringer Ingelheim, and Bayer, during the conduct of the study. Dr Shashank Joshi reports speaker fees from Torrent, during the conduct of the study; speaker fees from Eli Lilly, Abbott, Boehringer Ingelheim, Astra Zeneca, MSD, and PHFI; advisory for/from Sanofi, Franco India, Marico, Bayer Zydus, Roche Diabetes Care, Twin Health, and Zydus Cadila; speaker fees and advisory for/from Novo Nordisk, outside the submitted work. Professor Subhankar Chowdhury reports advisory board member for Glenmark, outside the submitted work. The authors report no other potential conflicts of interest in this work.

\section{References}

1. GBD 2016 Causes of Death Collaborators. Global, regional, and national age-sex specific mortality for 264 causes of death, 1980-2016: a systematic analysis for the Global Burden of Disease Study 2016. Lancet. 2017;390:1151-1210. doi:10.1016/S0140-6736(17)32152-9

2. Seiglie JA, Marcus M-E, Ebert C, et al. Diabetes prevalence and its relationship with education, wealth, and BMI in 29 low- and middle-income countries. Diabetes Care. 2020;43:767-775. doi:10.2337/dc19-1782

3. Mechanick JI. Adiposity-based chronic disease—obesity re-worked. US Endocrinol. 2016;12:102. doi:10.17925/USE.2016.12.02.102

4. Reinehr T. Lifestyle intervention in childhood obesity: changes and challenges. Nat Rev Endocrinol. 2013;9:607-614. doi:10.1038/nrendo.2013.149

5. Mechanick JI, Garber AJ, Grunberger G, Handelsman Y, Garvey WT. Dysglycemia-based chronic disease: an American Association of Clinical Endocrinologists position statement. Endocr Pract. 2018;24:995-1011. doi:10.4158/PS-2018-0139

6. Mechanick JI, Farkouh ME, Newman JD, Garvey WT. Cardiometabolic-based chronic disease, addressing knowledge and clinical practice gaps. $J$ Am Coll Cardiol. 2020;75:539-555. doi:10.1016/j.jacc.2019.11.046

7. Kalra S, Unnikrishnan AG, Baruah MP, Sahay R, Bantwal G. Metabolic and energy imbalance in dysglycemia-based chronic disease. Diabetes Metab Syndr Obes. 2021;14:165-184. doi:10.2147/DMSO.S286888

8. Di Pino A, DeFronzo RA. Insulin resistance and atherosclerosis: implications for insulin-sensitizing agents. Endocr Rev. 2019;40:1447-1467. doi:10.1210/er.2018-00141

9. Gobardhan SN, Dimitriu-Leen AC, van Rosendael AR, et al. Prevalence by computed tomographic angiography of coronary plaques in South Asian and white patients with type 2 diabetes mellitus at low and high risk using four cardiovascular risk scores (UKPDS, FRS, ASCVD, and JBS3). Am J Cardiol. 2017;119:705-711. doi:10.1016/j.amjcard.2016.11.029

10. Kelley DE. Skeletal muscle fat oxidation: timing and flexibility are everything. J Clin Invest. 2005;115:1699-1702. doi:10.1172/JCI25758

11. Goodpaster BH, Sparks LM. Metabolic flexibility in health and disease. Cell Metab. 2017;25:1027-1036. doi:10.1016/j.cmet.2017.04.015

12. Galgani JE, Moro C, Ravussin E. Metabolic flexibility and insulin resistance. Am J Physiol Endocrinol Metab. 2008;295:E1009-E1017. doi:10.1152/ajpendo. 90558.2008

13. Czech MP. Insulin action and resistance in obesity and type 2 diabetes. Nat Med. 2017;23:804-814. doi:10.1038/nm.4350

14. Muoio DM. Metabolic inflexibility: when mitochondrial indecision leads to metabolic gridlock. Cell. 2014;159:1253-1262. doi:10.1016/j. cell.2014.11.034

15. Wilcox G. Insulin and insulin resistance. Clin Biochem Rev. 2005;26:19-39. 
16. Gonzalez-Zacarias AA, Mavarez-Martinez A, Arias-Morales CE, Stoicea N, Rogers B. Impact of demographic, socioeconomic, and psychological factors on glycemic self-management in adults with type 2 diabetes mellitus. Front Public Health. 2016;4. doi:10.3389/fpubh.2016.00195

17. Popkin BM, Reardon T. Obesity and the food system transformation in Latin America. Obes Rev. 2018;19:1028-1064. doi:10.1111/obr.12694

18. Unger JB, Reynolds K, Shakib S, et al. Acculturation, physical activity, and fast-food consumption among Asian-American and Hispanic adolescents. J Community Health. 2004;29:467-481. doi:10.1007/s10900-004-3395-3

19. Fall CH. Non-industrialised countries and affluence. Br Med Bull. 2001;60:33-50. doi:10.1093/bmb/60.1.33

20. Iwelunmor J, Blackstone $\mathrm{S}$, Veira $\mathrm{D}$, et al. Toward the sustainability of health interventions implemented in sub-Saharan Africa: a systematic review and conceptual framework. Implement Sci. 2016;11(43):1-27.

21. Łuczyński W, Głowińska-Olszewska B, Bossowski A. Empowerment in the treatment of diabetes and obesity. J Diabetes Res. 2016;2016: e5671492. doi:10.1155/2016/5671492

22. Lopez Stewart G, Tambascia M, Rosas Guzmán J, et al. Control of type 2 diabetes mellitus among general practitioners in private practice in nine countries of Latin America. Rev Panam Salud Publica. 2007;22:12-20. doi:10.1590/S1020-49892007000600002

23. Anjana RM, Deepa M, Subashini R, et al. Temporal changes in diabetes prevalence and achievement of care goals in urban South Asia from 2010 to 2016 - the center for cardio-metabolic risk reduction in South Asia Study. Diabetic Med. 2021;38(e14424). doi:10.1111/dme.14424

24. Ali MK, Singh K, Kondal D, et al. Effectiveness of a multicomponent quality improvement strategy to improve achievement of diabetes care goals. Ann Intern Med. 2016;165:399-408. doi:10.7326/M15-2807

25. Chalmers J, Cooper ME. UKPDS and the legacy effect. N Engl J Med. 2008;359:1618-1620. doi:10.1056/NEJMe0807625

26. Pedersen O, Gaede P. Intensified multifactorial intervention and cardiovascular outcome in type 2 diabetes: the Steno- 2 study. Metabolism. 2003;52:19-23. doi:10.1016/S0026-0495(03)00213-0

27. Ueki K, Sasako T, Okazaki Y, et al. Effect of an intensified multifactorial intervention on cardiovascular outcomes and mortality in type 2 diabetes (J-DOIT3): an open-label, randomised controlled trial. Lancet Diabetes Endocrinol. 2017;5:951-964. doi:10.1016/S2213-8587(17)30327-3

28. Schofield JD, Liu Y, Rao-Balakrishna P, Malik RA, Soran H. Diabetes dyslipidemia. Diabetes Ther. 2016;7:203-219. doi:10.1007/s13300-016-0167-x

29. Non-HDL cholesterol and atherosclerotic cardiovascular disease. Available from: https://www.japi.org/x264d464/non-hdl-cholesterol-andatherosclerotic-cardiovascular-disease. Accessed January 20, 2022.

30. Boekholdt SM, Arsenault BJ, Mora S, et al. Association of LDL cholesterol, non-HDL cholesterol, and apolipoprotein B levels with risk of cardiovascular events among patients treated with statins: a meta-analysis. JAMA. 2012;307:1302-1309. doi:10.1001/jama.2012.366

31. Iyengar SS, Puri R, Narasingan SN. Lipid association of India expert consensus statement on management of dyslipidemia in Indians 2016 : part 1. J Assoc Physicians India. 2016;64:7-52.

32. Reiner Z, Catapano AL, De Backer G; Developed with the special contribution of: European Association for Cardiovascular Prevention \& Rehabilitation. ESC/EAS Guidelines for the management of dyslipidaemias: the Task Force for the management of dyslipidaemias of the European Society of Cardiology (ESC) and the European Atherosclerosis Society (EAS). Eur Heart J. 2011;32:1769-1818. doi:10.1093/eurheartj/ehr158

33. Anjana RM, Baskar V, Nair ATN, et al. Novel subgroups of type 2 diabetes and their association with microvascular outcomes in an Asian Indian population: a data-driven cluster analysis: the INSPIRED study. BMJ Open Diabetes Res Care. 2020;8(e001506). doi:10.1136/bmjdrc-2020-001506

34. Zou X, Zhou X, Zhu Z, Ji L. Novel subgroups of patients with adult-onset diabetes in Chinese and US populations. Lancet Diabetes Endocrinol. 2019;7:9-11. doi:10.1016/S2213-8587(18)30316-4

35. Anjana RM, Deepa M, Pradeepa R, et al. Prevalence of diabetes and prediabetes in 15 states of India: results from the ICMR-INDIAB populationbased cross-sectional study. Lancet Diabetes Endocrinol. 2017;5:585-596. doi:10.1016/S2213-8587(17)30174-2

36. Pati MK, Swaroop N, Kar A, et al. A narrative review of gaps in the provision of integrated care for noncommunicable diseases in India. Public Health Rev. 2020;8:41.

37. Patel SA, Sharma H, Mohan S, et al. The Integrated Tracking, Referral, and Electronic Decision Support, and Care Coordination (I-TREC) program: scalable strategies for the management of hypertension and diabetes within the government healthcare system of India. BMC Health Serv Res. 2020;20:1022. doi:10.1186/s12913-020-05851-w

38. Gupta M, Brister S, Verma S. Is South Asian ethnicity an independent cardiovascular risk factor? Can J Cardiol. 2006;22:193-197. doi:10.1016/ S0828-282X(06)70895-9

39. Kasliwal RR, Mahansaria K, Bansal M. Cardiovascular risk algorithms and their applicability to Indians; 2010.

40. Findlay SG, Kasliwal RR, Bansal M, Tarique A, Zaman A. A comparison of cardiovascular risk scores in native and migrant South Asian populations. SSM Popul Health. 2020;11:100594.

41. Bansal M, Kasliwal RR, Trehan N. Relationship between different cardiovascular risk scores and measures of subclinical atherosclerosis in an Indian population. Indian Heart J. 2015;67:332-340. doi:10.1016/j.ihj.2015.04.017

42. Lloyd-Jones Donald M, Leip EP, Larson MG, et al. Prediction of lifetime risk for cardiovascular disease by risk factor burden at 50 years of age. Circulation. 2006;113:791-798. doi:10.1161/CIRCULATIONAHA.105.548206

43. Daviglus ML. Cardiovascular risk profile earlier in life and medicare costs in the last year of life. Arch Intern Med. 2005;165(1028):1028. doi:10.1001/archinte.165.9.1028

44. Joseph P, Leong D, McKee M, et al. Reducing the global burden of cardiovascular disease, part 1. Circ Res. 2017;121:677-694. doi:10.1161/ CIRCRESAHA.117.308903

45. Suzanne O. Antihypertensive and Lipid-Lowering Treatment to Prevent Heart Attack Trial (ALLHAT). Hypertension. 2003;41:1006-1009. doi:10.1161/01.HYP.0000070905.09395.F6

46. Karachaliou F, Simatos G, Simatou A. The challenges in the development of diabetes prevention and care models in low-income settings. Front Endocrinol. 2020;11. doi:10.3389/fendo.2020.00518

47. Rushforth B, McCrorie C, Glidewell L, Midgley E, Foy R. Barriers to effective management of type 2 diabetes in primary care: qualitative systematic review. Br J Gen Pract. 2016;66:e114-e127. doi:10.3399/bjgp16X683509

48. Asif M. The prevention and control the type-2 diabetes by changing lifestyle and dietary pattern. J Educ Health Promot. 2014;3. doi:10.4103/22779531.127541

49. Liu K, Daviglus ML, Loria CM, et al. Healthy lifestyle through young adulthood and presence of low cardiovascular disease risk profile in middle age: the coronary artery risk development in (Young) Adults (CARDIA) Study. Circulation. 2012;125:996-1004. doi:10.1161/ CIRCULATIONAHA.111.060681 
50. Uusitupa M. Good news from the Da Qing Diabetes Prevention Outcome Study—healthy lifestyles result in long-term cardiovascular benefits. Ann Transl Med. 2019;7:S368-S368. doi:10.21037/atm.2019.08.123

51. Thankappan KR, Sathish T, Tapp RJ, et al. A peer-support lifestyle intervention for preventing type 2 diabetes in India: a cluster-randomized controlled trial of the Kerala Diabetes Prevention Program. PLoS Med. 2018;15:e1002575. doi:10.1371/journal.pmed.1002575

52. Yu E, Malik VS, Hu FB. Cardiovascular disease prevention by diet modification: JACC Health Promotion Series. J Am Coll Cardiol. 2018;72:914-926. doi:10.1016/j.jacc.2018.02.085

53. Misra A, Sharma R, Gulati S, et al. Consensus dietary guidelines for healthy living and prevention of obesity, the metabolic syndrome, diabetes, and related disorders in Asian Indians. Diabetes Technol Ther. 2011;13:683-694. doi:10.1089/dia.2010.0198

54. Mattei J, Malik V, Wedick NM, et al. A symposium and workshop report from the global nutrition and epidemiologic transition initiative: nutrition transition and the global burden of type 2 diabetes. Br J Nutr. 2012;108:1325-1335. doi:10.1017/S0007114512003200

55. World Health Organization \& Commission on Ending Childhood Obesity. Report of the commission on ending childhood obesity; 2016.

56. Weber MB, Ranjani H, Staimez LR, et al. The stepwise approach to diabetes prevention: results from the D-CLIP Randomized Controlled Trial. Diabetes Care. 2016;39:1760-1767. doi:10.2337/dc16-1241

57. Goff DC, Lloyd-Jones DM, Bennett G, et al. 2013 ACC/AHA guideline on the assessment of cardiovascular risk: a report of the American College of Cardiology/American Heart Association Task Force on Practice Guidelines. Circulation. 2014;129:S49-S73. doi:10.1161/01. cir.0000437741.48606.98

58. World Health Organization. More active people for a healthier world: global action plan on physical activity 2018-2030; 2018.

59. Carey RM, Muntner P, Bosworth HB, Whelton PK. Prevention and control of hypertension: JACC health promotion series. J Am Coll Cardiol. 2018;72:1278-1293. doi:10.1016/j.jacc.2018.07.008

60. Correia JC, Lachat S, Lagger G, et al. Interventions targeting hypertension and diabetes mellitus at community and primary healthcare level in lowand middle-income countries: a scoping review. BMC Public Health. 2019;19(1542). doi:10.1186/s12889-019-7842-6

61. Wing RR, Phelan S. Long-term weight loss maintenance. Am J Clin Nutr. 2005;82:222S-225S. doi:10.1093/ajcn/82.1.222S

62. Griffin SJ, Borch-Johnsen K, Davies MJ, et al. Effect of early intensive multifactorial therapy on 5-year cardiovascular outcomes in individuals with type 2 diabetes detected by screening (ADDITION-Europe): a cluster-randomised trial. Lancet. 2011;378:156-167. doi:10.1016/S01406736(11)60698-3

63. Cosentino F, Grant PJ, Aboyans V, et al. 2019 ESC Guidelines on diabetes, pre-diabetes, and cardiovascular diseases developed in collaboration with the EASD. Eur Heart J. 2020;41(2):255-323. doi:10.1093/eurheartj/ehz486

64. Hauner H. The mode of action of thiazolidinediones. Diabetes Metab Res Rev. 2002;18(Suppl 2):S10-15. doi:10.1002/dmrr.249

65. Miyazaki Y, Mahankali A, Matsuda M, et al. Effect of pioglitazone on abdominal fat distribution and insulin sensitivity in type 2 diabetic patients. J Clin Endocrinol Metab. 2002;87:2784-2791. doi:10.1210/jcem.87.6.8567

66. Perry RJ, Shulman GI. Sodium-glucose cotransporter-2 inhibitors: understanding the mechanisms for therapeutic promise and persisting risks. J Biol Chem. 2020;295:14379-14390. doi:10.1074/jbc.REV120.008387

67. Solis-Herrera C, Daniele G, Alatrach M, et al. Increase in endogenous glucose production with SGLT2 inhibition is unchanged by renal denervation and correlates strongly with the increase in urinary glucose excretion. Diabetes Care. 2020;43:1065-1069. doi:10.2337/dc19-2177

68. Husain M, Bain SC, Holst AG, et al. Effects of semaglutide on risk of cardiovascular events across a continuum of cardiovascular risk: combined post hoc analysis of the SUSTAIN and PIONEER trials. Cardiovasc Diabetol. 2020;19(156). doi:10.1186/s12933-020-01106-4

69. Nagahisa T, Saisho Y. Cardiorenal protection: potential of SGLT2 inhibitors and GLP-1 receptor agonists in the treatment of type 2 diabetes. Diabetes Ther. 2019;10:1733-1752. doi:10.1007/s13300-019-00680-5

70. Pernicova I, Korbonits M. Metformin — mode of action and clinical implications for diabetes and cancer. Nat Rev Endocrinol. 2014;10:143-156. doi:10.1038/nrendo.2013.256

71. Zhou G, Myers R, Li Y, et al. Role of AMP-activated protein kinase in mechanism of metformin action. J Clin Invest. 2001;108:1167-1174. doi:10.1172/JCI13505

72. Lopaschuk GD, Verma S. Mechanisms of cardiovascular benefits of Sodium Glucose Co-Transporter 2 (SGLT2) inhibitors. JACC Basic Transl Sci. 2020;5:632-644. doi:10.1016/j.jacbts.2020.02.004

73. Halimi S, Vergès B. Adverse effects and safety of SGLT-2 inhibitors. Diabetes Metab. 2014;40(S28-S34):S28-S34. doi:10.1016/S1262-3636(14) 72693-X

74. Costello RA, Nicolas S, Shivkumar A. Sulfonylureas. In: StatPearls. StatPearls Publishing; 2021.

75. Lebovitz HE. Thiazolidinediones: the forgotten diabetes medications. Curr Diab Rep. 2019;19(151). doi:10.1007/s11892-019-1270-y

76. Deacon CF. Dipeptidyl peptidase 4 inhibitors in the treatment of type 2 diabetes mellitus. Nat Rev Endocrinol. 2020;16:642-653. doi:10.1038/ s41574-020-0399-8

77. Tran KL, Park YI, Pandya S, et al. Overview of glucagon-like peptide-1 receptor agonists for the treatment of patients with type 2 diabetes. Am Health Drug Benefits. 2017;10:178-188.

78. Hinnen D. Glucagon-like peptide 1 receptor agonists for type 2 diabetes. Diabetes Spectr. 2017;30:202-210. doi:10.2337/ds16-0026

79. van de Laar FA, Lucassen PL, Akkermans RP, et al. $\alpha$-Glucosidase inhibitors for patients with type 2 diabetes: results from a Cochrane systematic review and meta-analysis. Diabetes Care. 2005;28:154-163. doi:10.2337/diacare.28.1.154 


\section{Publish your work in this journal}

Diabetes, Metabolic Syndrome and Obesity: Targets and Therapy is an international, peer-reviewed open-access journal committed to the rapid publication of the latest laboratory and clinical findings in the fields of diabetes, metabolic syndrome and obesity research. Original research, review, case reports, hypothesis formation, expert opinion and commentaries are all considered for publication. The manuscript management system is completely online and includes a very quick and fair peer-review system, which is all easy to use. Visit http://www.dovepress. com/testimonials.php to read real quotes from published authors.

Submit your manuscript here: https://www.dovepress.com/diabetes-metabolic-syndrome-and-obesity-targets-and-therapy-journal 